\title{
HEPATITE FULMINANTE E FEBRE NEGRA DE LÁBREA: ESTUDO DE 5 CASOS PROCEDENTES DE CODAJÁS, AMAZONAS, BRASIL
}

\author{
José Carlos Ferraz da Fonseca, Luiz Carlos Lima Ferreira, Ana Luiza Pereira \\ da Silva Guerra, Leni Mota Passos e José Pascoal Simonetti
}

São descritas as manifestações clinicas, laboratoriais e aspectos evolutivos de cinco pacientes procedentes de Codajás-Amazonas, atendidos no Instituto de Medicina Tropical de Manaus devido ao quadro de hepatopatia grave, com periodo médio de doença de quatro dias. Quatro destes pacientes evoluiram para óbito, com uma média de cinco dias desde o inicio dos pródromos. A sorologia para hepatite $\mathrm{B}$ mostrou que o $\mathrm{Ag} \mathrm{HBs}$ estava presente em quatro e o Anti - $\mathrm{HBc}$ em todos. Dos pacientes que foram ao óbito, através da necropsia a histopatologia do fígado revelou quadro de hepatite fulminante em dois e de febre de Lábrea nos outros dois.

Palavras chaves: Hepatite fulminante. Febre de Lábrea.

As hepatites por vírus em algumas áreas da região amazônica apresentam características endêmicas, sendo que a forma fulminante ganha ainda maior complexidade por apresentar padrões clíni$\cos$ e histopatologia diferentes. Nessa diferença, uma entidade denominada febre negra de Lábrea, doença própria da região amazônica, ocorrendo sob a forma de microepidemias, tem sido descrita ao longo do Rio Purús, acometendo principalmente crianças e adultos jovens, e, na maioria das vezes, membros de uma mesma família, porém sem uma etiologia definida ${ }^{3-6} 8^{81-13}$. A relação entre hepatite B e antígeno Austrália está perfeitamente estabelecida ${ }^{2}$. Há por outro lado, uma possível relação entre antígeno Austrália e a febre negra de Lábrea ${ }^{1}$.

Neste trabalho estamos descrevendo o quadro clínico, aspectos evolutivos e o encontro do $\mathrm{Ag} \mathrm{HBs} \mathrm{e} \mathrm{Anti} \mathrm{-} \mathrm{HBc} \mathrm{no} \mathrm{soro} \mathrm{de} \mathrm{pacientes} \mathrm{com}$ hepatite fulminante e de febre negra de Lábrea.

\section{MATERIAL E MÉTODOS}

Entre julho e agosto de 1981, cinco pacientes procedentes de Codajás, Amazonas, foram in-

Trabalho do Instituto de Medicina Tropical de Manaus, Faculdade de Ciências da Saúde da Universidade Federal do Amazonas e Instituto Oswaldo Cruz, Fundação Oswaldo Cruz, Rio de Janeiro.

Recebido para publicação em 5/1/83. ternados no Instituto de Medicina Tropical de Manaus, com quadro clínico de hepatopatia grave.

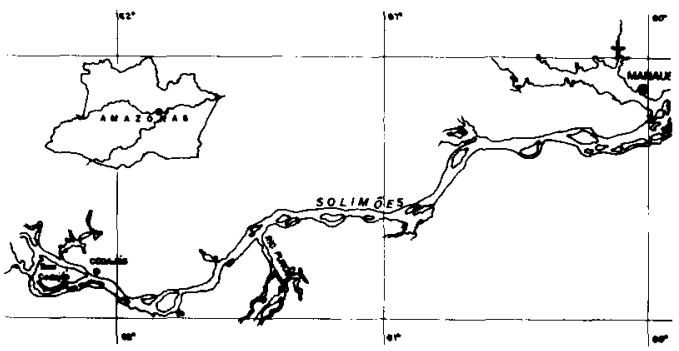

Figura 1 - Localizaçăo de Codajás no Estado do Amazonas, procedência dos casos de hepatite fulminante e febre negra de Lábrea.

Procedeu-se a uma avaliação clínica de cada caso e no momento da internação foram feitos os seguintes exames auxiliares do diagnóstico: hemograma completo, transaminase oxalacética e pirúvica (método de Reitman e Frankel), bilirrubinas (método Jendrassik e Grof modificado). De todos os pacientes foram colhidas duas alíquotas de soro e enviadas ao Instituto Oswaldo Cruz, Rio de Janeiro, para pesquisa sorológica do VHB, e a outra ao Instituto Evandro Chagas, Belém, PA, para realização de provas sorológicas para arbovírus. A sorologia para hepatite $B$, a pesquisa do $\mathrm{Ag} \mathrm{HBs}$ e Anti - $\mathrm{HBc}$, foi realizada por radioimunoensaio. Quanto à sorologia para arboviroses, não foi possível realizá-la, por dificuldades operacionais. Em relação a terapêutica, todos os pacientes receberam tratamento sintomático, através de reposição 
Fonseca JCF, Ferretra LCL, Guerra ALPS, Passos LM, Simonetti JP. Hepatite fulminante e Febre Negra de Labrea: Estudo de 5 casos procedentes de Codajas, Amazonas, Brasil. Revista da Sociedade Brasileira de Medicina Tropical 16:144147, Jul/Set, 1983

calórica, vitamina $\mathrm{K} 1$, esterilização da flora bacteriana e reposição sangüínea.

Dos pacientes que foram ao óbito, foi realizada necropsia com o estudo da histopatologia do fígado, corando-se o tecido pela hematoxilina eosina, prata e tricrômico de Gomori.

\section{RESULTADOS}

Dos cinco pacientes, quatro eram do sexo masculino e um do sexo feminino. A faixa etária variou de 7 a 22 anos (média 13 anos). Nos casos que evoluíram para o óbito, (casos $1,2,3$ e 4) a duração média da doença foi de cinco dias desde o início dos pródromos, sendo que o caso 5 recebeu alta após 26 dias de internação. Quanto à sintomatologia observada no quadro inicial, verificamos febre em todos os cinco casos, icterícia discreta e dor epigástrica em quatro, náuseas e vômitos em três e hepatomegalia em dois. Apenas um paciente apresentava agitação psicomotora (Tabela 1). Em relação ao quadro evolutivo, em todos houve intensificação do quadro ictérico, agitação psicomotora, hematêmese e coma hepático, tendo o caso 5 permanecido em coma hepático por 3 dias com evolução clínica favorável.

Tabela 1 - Dados clinicos gerais observados inicialmente nos pacientes com hepatite fulminante e febre negra de Labrea em Codajais, Amazonas.

\begin{tabular}{|c|c|c|c|c|c|c|c|c|c|c|c|}
\hline \multirow{2}{*}{ Casos } & \multirow{2}{*}{ Iniciais } & \multirow{2}{*}{ Sexo } & \multirow{2}{*}{$\begin{array}{c}\text { Idade } \\
\text { (anos) }\end{array}$} & \multirow{2}{*}{$\begin{array}{c}\text { Tempo de } \\
\text { doença } \\
\text { (dias) }\end{array}$} & \multicolumn{7}{|c|}{ Manifestações clínicas } \\
\hline & & & & & Febre & Ictericia & Dor. Epigt. & Náuseas & Vômitos & Hepatomegalia & Agit. psicomotora \\
\hline 1 & JBO & $\mathbf{M}$ & 22 & 7 & + & + & + & + & + & - & + \\
\hline 2 & LST & $\mathbf{M}$ & 20 & 4 & + & + & + & + & + & + & - \\
\hline 3 & RJB & $\mathbf{M}$ & 08 & 2 & + & - & + & - & + & + & - \\
\hline 4 & APS & $\mathrm{F}$ & 07 & 2 & + & + & + & - & - & - & - \\
\hline 5 & JSG & $\mathbf{M}$ & 08 & 3 & + & + & - & + & - & - & - \\
\hline
\end{tabular}

+ presente

- ausente

O leucograma revelou leucocitose em quatro casos e linfocitose absoluta em todos, a bilirrubina total foi acentuada em quatro (acima de $12,5 \mathrm{mg} \%$ ), havendo predominância de bilirrubina direta (média $11,66 \mathrm{mg} \%)$. Com relação às transaminases, ob- servamos uma variação da transaminase pirúvica de 1.400 a 3.600 UI (média 2.048 UI), com máxima elevação no caso 3 . $\mathrm{O}$ anti-HBc foi positivo em todos e o Ag HBs em quatro casos (Tabela 2).

Tabela 2 - Resultados dos exames laboratoriais nos pacientes de hepatite fulminante e febre negra de Lábrea em Codajás, Amazonas.

\begin{tabular}{|c|c|c|c|c|c|}
\hline \multirow[b]{2}{*}{ Exames } & \multicolumn{5}{|c|}{ Casos } \\
\hline & 1 & 2 & 3 & 4 & 5 \\
\hline Leucócitos $/ \mathrm{mm}^{3}$ & 11.000 & 19.700 & 7.000 & 15.000 & 11.900 \\
\hline Bilirrubina total (mg\%) & 16,5 & 16,0 & 5,3 & 12,5 & 12,5 \\
\hline direta & 14,0 & 14,0 & 4,0 & 9,5 & 9,25 \\
\hline indireta & 2,5 & 2,0 & 1,3 & 3,0 & 3,25 \\
\hline Transaminases (UI): & & & & & \\
\hline TGO & 610 & 1.800 & 2.100 & 1.600 & 1.000 \\
\hline TGP & 1.500 & 1.940 & 3.600 & 1.800 & 1.400 \\
\hline $\mathrm{Ag} \mathrm{HBs}$ & + & + & - & + & + \\
\hline Anti - HBc & + & + & + & + & + \\
\hline
\end{tabular}


Nos quatro pacientes necropsiados (casos 1 , 2,3 e 4), encontramos os seguintes achados histopatológicos: em dois casos ( 1 e 2), caracterizando a hepatite fulminante, os cortes mostram necrose extensa e difusa do parênquima hepático, com a presença de corpúsculos hialinos do tipo Councilman (Fig. 2) e substituição dos hepatócitos por um infiltrado denso, constituído por linfócitos, plasmócitos e histiócitos; houve ainda de permeio extensas áreas de sufusões hemorrágicas. Em um desses casos, observou-se regeneração dos hepatócitos, com formação pseudo-acinosas - contendo trombos biliares na porção central - e poliploidia nuclear. Os espaços porta estavam repletos de lin. fócitos, monócitos e polimorfonucleares neutröfilos, a par da proliferação ductular. Em algumas áreas ocorria colapso da trama de fibras reticulares que suporta as placas de hepatócitos.

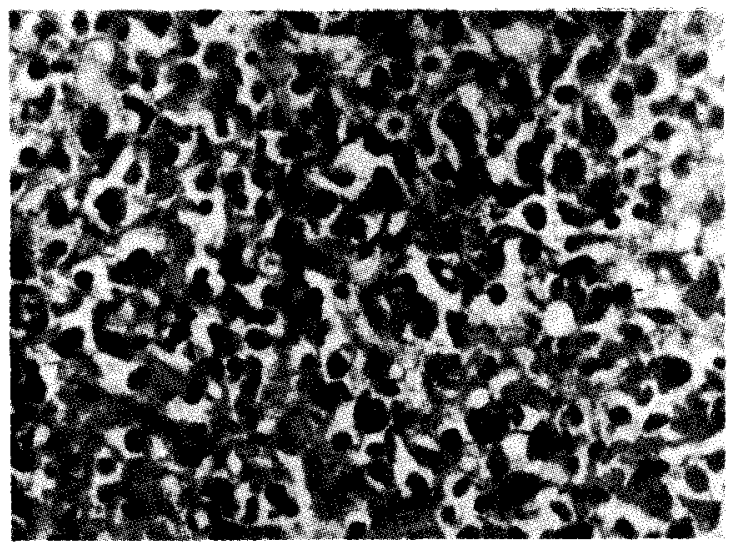

Figura 2 - Fígado com fenômenos regressivos dos hepatócitos e inúmeros corpúsculos tipo Councilman (hematoxilina-eosina $\times 400$ ).

Caracterizando a febre negra de Lábrea, nos outros dois casos, ( 3 e 4), observou-se degeneração intensa dos hepatócitos, sem distribuição preferencial no interior dos lóbulos. Tais hepatócitos, tumefeitos, freqüentemente exibem multivacuolização citoplasmática proeminente, mantendo o núcleo na sua posição central; são as conhecidas células em "mórula" ou "aranha", da hepatite de Lábrea (Fig. 3). Ao lado destas células, que se coram positivamente para gordura, viam-se hepatócitos em necrose de coagulação e necrose lítica. Infiltração de linfócitos, macrófagos e raros neutrófilos estavam presentes em espaços porta e dentro dos lóbulos (Fig. 3). Não foram evidenciados, em ambos os casos, fenômenos regenerativos dos hepatócitos ou colapso da trama reticular.

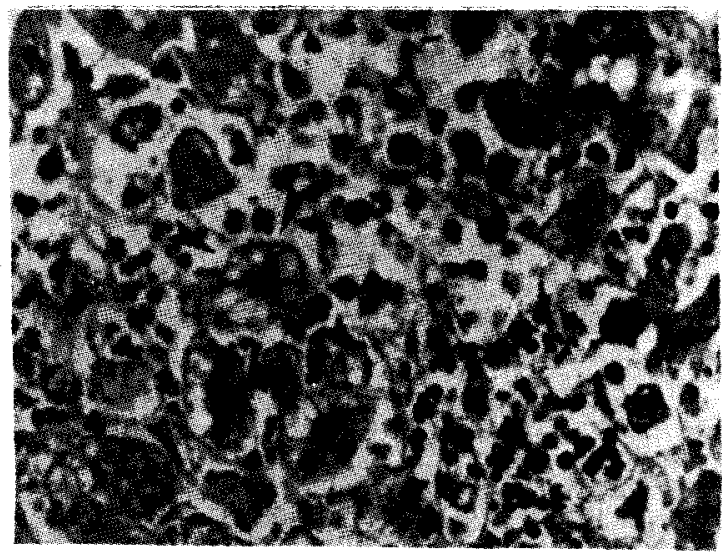

Figura 3 - Fígado com degeneração morular com múltiplos vacúolos intra-citoplasmáticos (hematoxilina-osina X 400).

\section{DISCUSSÃO}

A ocorrência da febre negra de Lábrea em outras áreas da Amazônia, evidenciada neste trabalho (Codajás - Amazonas) (Fig. 1) torna patente que a referida entidade não estaria restrita ao Rio Purús e, em especial, ao Município de Lábrea. São bem conhecidas as lesões anatômicas que ocorrem no tecido hepático caracterizadas pela presença de células em "mórula" ou "aranha", e que se diferenciam dos quadros clássicos de hepatite fulminante pelo vírus das hepatites. Hipóteses surgiram tentando diferenciar a febre negra de Lábrea das outras hepatopatias comuns na região amazônica, como a hepatite infecciosa, leptospirose, febre amarela e arboviroses 671011 .

A possibilidade de tóxicos como agentes etiológicos tem sido discutida, incriminando-se as aflatoxinas como contaminantes dos alimentos ${ }^{4}$ e o "timbó" (Derris negrensis), utilizado para pesca por habitantes da região (HV Dourado: comunicação pessoal, 1981). A ação do Derris negrensis em animais de sangue quente provocaria inibição da cadeia respiratória, pela capacidade de deprimir o consumo de oxigênio, além de alterações mitocondriais $^{14}$.

Em um surto de febre negra ocorrido no $\mathrm{Mu}$ nicípio de Lábrea ${ }^{1}$, o antígeno Austrália foi encontrado na fase aguda e verificou-se sua negativação na fase de convalescença, sugerindo que o vírus da hepatite $B$ teria significativa importância na etiologia da febre negra.

Quanto aos casos que estamos descrevendo, 
Fonseca JCF, Ferreira LCL, Guerra ALPS, Passos LM, Simonetti JP. Hepatite fulminante e Febre Negra de Lábrea: Estudo de 5 casos procedentes de Codajás, Amazonas, Brasil. Revista da Sociedade Brasileira de Medicina Tropical 16:144-147, Jul/Set, 1983

os achados clínicos iniciais dos pacientes com diagnóstico de febre negra de Lábrea confirmados pela necropsia em nada diferem do relato de outros autores $^{12}{ }^{13}$. Com relação aos aspectos evolutivos, seja a hepatite fulminante ou febre negra de Lábrea, não encontramos diferenças que, clinicamente, pudéssemos distinguir em entidades separadas e sim somente através dos estudos histopatolígicos realizados nestes pacientes.

Nos achados sorológicos, verificamos que existia replicação viral (Anti-HBc) em todos, quer fôssem hepatite fulminante ou febre negra de Lábrea, e o $\mathrm{Ag} \mathrm{HBs}$ positivo em quatro, inclusive em um onde a histopatologia foi de febre negra. Esses achados estreitam a relação entre a febre negra e VHB como etiologia, merecendo uma análise longitudinal para explicar se a febre negra de Lábrea constitui um quadro nosológico isolado ou apenas uma fase evolutiva da hepatite a vírus, já que a presença do Ag HBs e do Anti - $\mathrm{HBc}$ com reatividade sorológica indicaria HVB aguda ou estado de portador crônico ${ }^{9}$. A presença do Anti - $\mathrm{HBc}$ sugere indicador do vírus da hepatite $\mathrm{B}$ em duplicação e constitui um indicador mais sensivel da presença do VHB do que a detecção do $\mathrm{Ag} \mathrm{HBs}^{11}$.

\section{SUMMARY}

We have described the clinical and laborato$r y$ manifestations and evolutional aspects of five patients from Codajás, state of Amazonas, Brasil. These patients were treated at the Instituto de Medicina Tropical de Manaus with a picture of acute liver failure with an average period of evolution of 4 days. Of these patients, four died, within an average time of five days since the prodromal phase. Serology for hepatitis $B$ showed that HBAg was present in four, and the $H B C$ antigen in all patients.

An autopsy was perfomed on the four patients who died, and the liver histopathology revealed a picture of fulminant hepatitis in two, and Labrea fever (febre negra), in the other two. fever.

Key words: Fulminant viral hepatitis. Lábrea

\section{REFERENNCIAS BIBLIOGRÁFICAS}

1. Bensabath G, Boshell J. Presença do antígeno Austrália (AU) em população do in terior do Estado do
Amazonas, Brasil. Revista do Instituto de Medicina Tropical de São Paulo 15: 284-288, 1983.

2. Blumberg BS. Australia antigen and hepatitis. New England Journal of Medicine 283-349, 1970.

3. Boshell JM. Report on the Labrea region epidemic. September-November 1965. In: Belem Virus Laboratory Annual Report, Belém-Pará, FSESP, 1965.

4. Boshell JM. Studies on the Amazonian fever (febre de Lábrea: febre negra etc). In: Belem Virus Laboratory Annual Report, Belém-Pará, FSESP, 1966.

5. Boshell JM. Labrea fever (febre negra) studies. In: Belem Virus Laboratory Annual Report, Belém-Pará, FSESP, 1967.

6. Costa EA. Febre negra do Rio Purús. Gazeta Médica da Bahia 3:148-175, 1970.

7. De Paola D, Pinheiro AF, Dias LB, Lacerda PRS. A febre negra da Amazônia. O Hospital 71: 1303-1311, 1967.

8. Dias LB, Moraes M. Hepatite de Lábrea. Revista do Instıtuto de Medicina Tropical de São Paulo 15:86$-93,1973$.

9. Hoofnagle JH. Serologic markers of hepatitis B virus infection. Anais da Revista Médica 32:1-11, 1981.

10. Hoofnagle JH, Gerety RJ, Ni LY. Antibody to hepatitis $B$ core antigen. A sensitive indicator of hepatitis B virus replication. New England Journal of Medicine 290: 1336-1340, 1974.

11. Prata A, Bina JC, Dourado HV, Andrade Z. Apresentação de um caso de febre negra no Rio Purús. Revista da Sociedade Brasileira de Medicina Tropical $6: 438,1972$.

12. Rodrigues $F^{\circ}$. A, Salles JM, Vianna $C N$, Leitão $E G$. Febre negra: considerações sobre aspectos clínicos. Revista da Universidade Federal do Pará 1:321-342, 1971.

13. Santos JB. Febre negra na região de Lábrea, AM. Estudo clínico, epidemiológico e histopatológico. Tese de Mestrado, Universidade de Brasília, Brasília, 1978.

14. Vianna CHM, Odebrecht S, Campello AP, Dourado HV. Ação tóxica de extratos de Derris negrensis (timbó) "in vivo" e "in vitro". Arquivos de Biologia e Tecnologia 22:95-109, 1979. 